\title{
Optimization of the properties obtained by quenching in martensitic stainless steels X30-40Cr13 and X40-60CrMoV14
}

\author{
C. GARCIA DE ANDRES, L. F. ALVAREZ \\ Centro Nacional de Investigaciones Metalúrgicas (CENIM-CSIC), Departamento de Procesos \\ de Transformación Y Fundición Avda. Gregorio del Amo, 8-28040 Madrid, Spain
}

An experimental study of the effects produced by different parameters of the heat-quenching cycle permitted the optimization of the properties typical of these martensitic stainless steels: hardness and corrosion resistance. The results obtained demonstrate that the heating temperatures currently used in industrial quenching treatment of these steels should be modified.

\section{Introduction}

Scientific knowledge of the phenomena related to heat treatment of materials has evolved to such an extent over recent years that a review is needed of the parameters used in industrial quenching treatment of martensitic stainless steels.

The factors which affect the properties obtained in steels by heat treatment are well known. Since Brearley developed martensitic stainless steels in 1913, however, the approach and properties of the quenching treatment of these steels have remained practically unchanged. Numerous standards and current research projects on these steels $[1-7]$, still specify quenching parameters very similar to those of the first studies compiled in the work of Kinzel et al. [8].

In general, the basic properties required from martensitic stainless steels are high hardness and high corrosion resistance. To optimize both properties simultaneously, an experimental evaluation was made of the effects of the heating temperature and cooling rate on the properties obtained by heat-quenching treatment in the four steels listed in Table I. These steels are supplied in spheroidized annealing form, with microstructures of finely distributed $\mathrm{M}_{23} \mathrm{C}_{6}$ carbides in a ferrite matrix (Fig. 1). The whole experimental study described was conducted from this initial metallurgical state.

\section{Influence of heating temperature}

\subsection{Hardness}

To evaluate the specific influence of the heating temperature on the quenching hardness of the steels studied, heat-quenching treatments were conducted at different temperatures while the other heat-cycle parameters were kept constant. Test pieces $2 \mathrm{~mm}$ thick and $12 \mathrm{~mm}$ long were heated at a constant rate of $0.5 \mathrm{~K} \mathrm{~s}^{-1}$ in a tungsten resistor furnace, equipped with ultrasensitive electronic programming, control and regulation systems. Radiation was focalized on the samples, which were kept at the different heating temperatures for $60 \mathrm{~s}$ and cooled at a constant rate of $2 \mathrm{~K} \mathrm{~s}^{-1}$

Fig. 2 shows the variation of the quenching hardness in relation to the heating temperature. When the heating temperature was raised, in all the steels tested the quenching hardness increased until it reached a maximum value, after which it dropped with higher temperatures. This increase in hardness is the result of the larger concentration of carbon and of alloying elements in the austenitic solid solution, which in turn is the result of greater carbide dissolution and diffusion of carbide-forming elements during heating when the temperature increases. The level of hardness begins to drop after it has reached a maximum, because residual austenite is now present. The soluteenrichment of the austenite causes the temperatures of the martensitic transformation points $M_{\mathrm{s}}$ and $M_{\mathrm{f}}$ to drop as the heating temperatures rise $[9,10]$. Starting at the heating temperature at which $M_{\mathrm{f}}$ is equal to the room temperature, the rise in this temperature produces increasing amounts of residual austenite in the quenching microstructure and this leads to the steady lowering of its hardness.

The heating temperatures at which the maximum quenching hardnesses are reached in the four steels tested and their respective values are given in Table II. In terms of hardness, these temperatures may obviously be considered the optimum quenching temperatures of these martensitic stainless steels. Yet heating temperatures lower than these are still being used. Under the heading of "conventional temperatures", Table II shows the maximum temperatures generally used in industrial heat-quenching treatment of these steels [1-7] and also the quenching hardnesses obtained at these temperatures. It is clear that if the heating temperatures are raised from the conventional to the optimum levels, the quenching hardness of the 

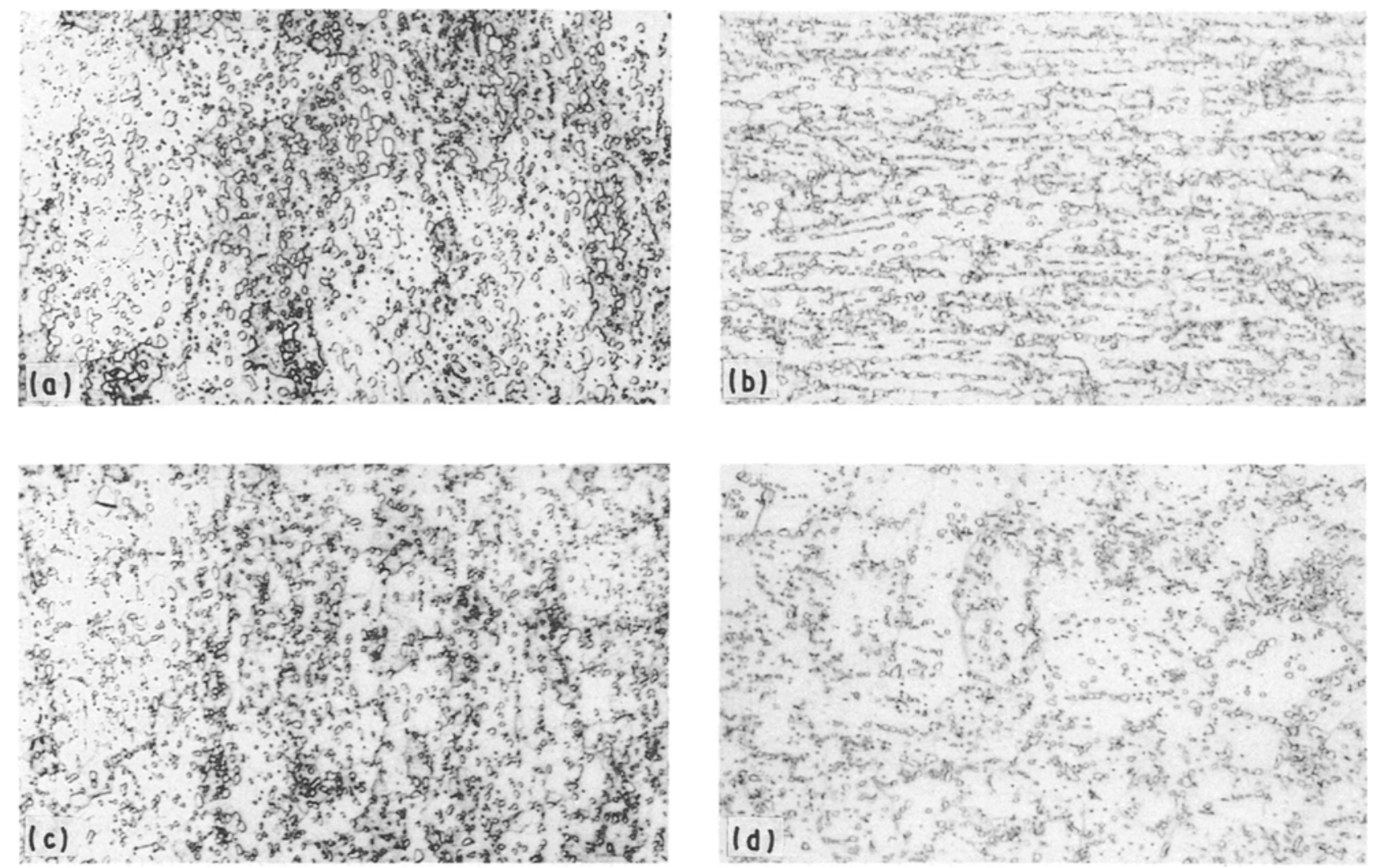

Figure 1 As-spheroidized annealing microstructures ( $\times 800$ ). Initial state of the steels. (a) X60CrMoV14, (b) X45CrMoV14, (c) X45Cr13, (d) $\mathrm{X} 30 \mathrm{Cr} 13$.

TABLE I Chemical composition (mass \%)

\begin{tabular}{llllllllll}
\hline Steel & $\mathrm{C}$ & $\mathrm{Si}$ & $\mathrm{Mn}$ & $\mathrm{P}$ & $\mathrm{S}$ & $\mathrm{Cr}$ & $\mathrm{Ni}$ & $\mathrm{Mo}$ & $\mathrm{V}$ \\
\hline X60CrMoV14 & 0.61 & 0.30 & 0.47 & 0.016 & 0.015 & 14.1 & 0.17 & 0.52 & 0.19 \\
X45CrMoV14 & 0.46 & 0.46 & 0.44 & 0.018 & 0.003 & 14.3 & 0.16 & 0.51 & 0.13 \\
X45Cr13 & 0.45 & 0.32 & 0.44 & 0.030 & 0.016 & 13.0 & 0.38 & & \\
X30Cr13 & 0.27 & 0.26 & 0.40 & 0.015 & 0.007 & 13.4 & 0.10 & & \\
\hline
\end{tabular}

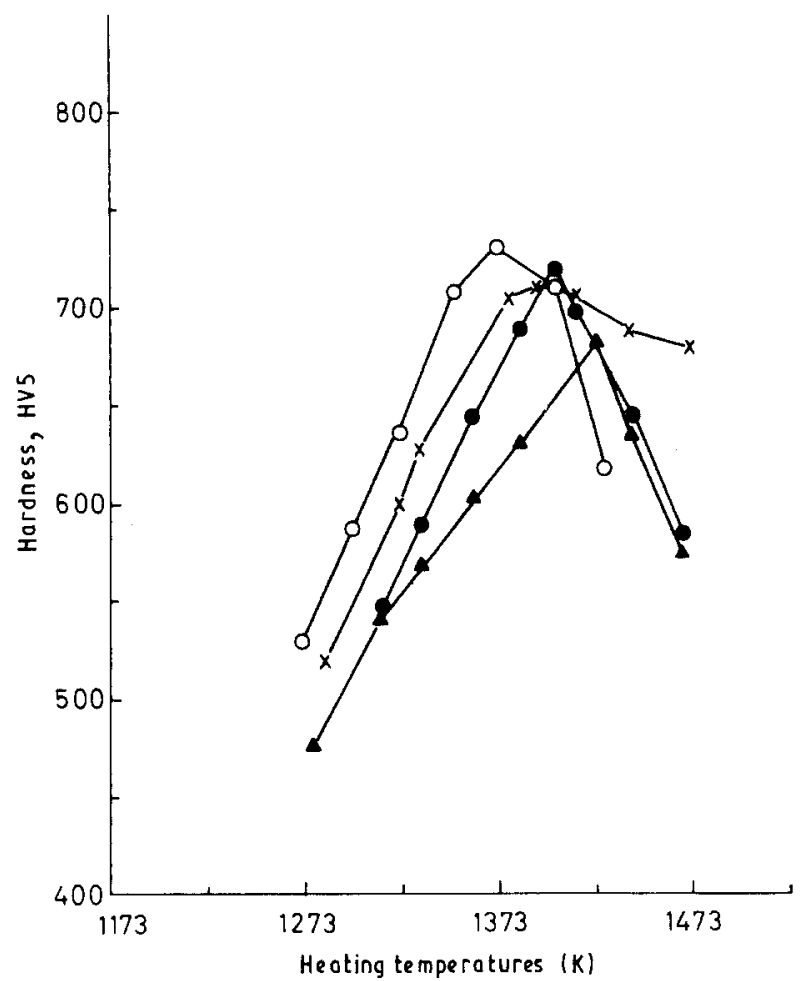

Figure 2 Influence of heating temperature on quenching hardness. (O) X60CrMoV14, (@) X45CrMo14, (x) X45Cr13, (4) X30Cr13. steels studied rises considerably. The effects of this temperature increase on austenitic grain growth and carbide dissolution are analysed below.

\subsection{Austenitic grain growth}

To analyse experimentally austenitic grain growth in these steels, an image analyser was used to measure the size of the austenitic grain of each microstructure obtained in the quenching tests described above. Fig. 3 shows the increase of the average austenitic grain diameter produced in these steels by raising the heating temperature. The graphs show that the austenitic grain size is controlled by the action of the carbides which remain undissolved in the austenite during heating. The average austenitic grain diameter measured at the conventional and optimum temperatures of each steel demostrate that in the three steels with the largest carbon content there is a moderate grain growth between both temperatures, and the austenitic grain remains fine at its corresponding optimum temperatures. In ranges of higher heating temperatures there is a greater grain growth. As will be seen below, raising the heating temperature causes the partial or total dissolution of carbides and so 


\begin{tabular}{lllll}
\hline Steel & $\begin{array}{l}\text { Conv. temp. } \\
(\mathrm{K})\end{array}$ & $\begin{array}{l}\text { Hardness } \\
\text { HV5 }\end{array}$ & $\begin{array}{l}\text { Optim. temp. } \\
(\mathrm{K})\end{array}$ & $\begin{array}{l}\text { Maximum } \\
\text { hardness HV5 }\end{array}$ \\
\hline X60CrMoV14 & 1323 & 635 & 1373 & 730 \\
X45CrMoV14 & 1313 & 545 & 1403 & 720 \\
X45Cr13 & 1333 & 630 & 1393 & 710 \\
X30Cr13 & 1313 & 550 & 1423 & 680 \\
\hline
\end{tabular}

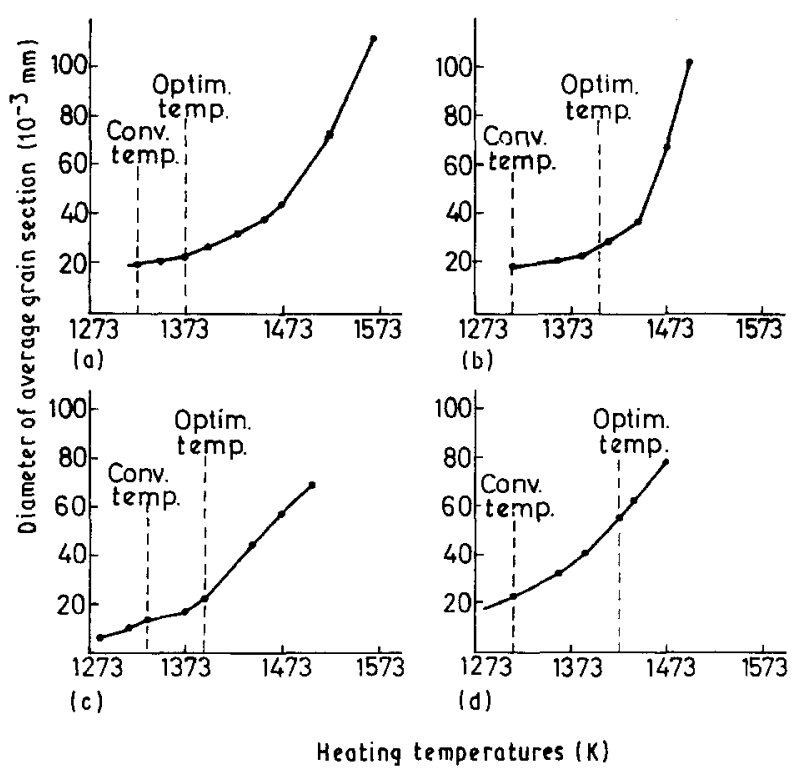

Figure 3 Austenitic grain growth versus heating temperature. (a) X60CrMoV14, (b) X45CrMoV14, (c) X45Cr13, (d) X30Crl3.

reduces or removes, respectively, their bumper effect on the austenitic grain growth.

At the same heating temperature, steel X30Cr13 has the largest grain sizes of the four steels studied. In addition, unlike the three steels with the largest carbon content, in steel $\mathrm{X} 30 \mathrm{Cr} 13$ there is a considerable growth of the austenitic grain between its conventional and optimum temperatures. As this steel has the lowest carbon content, there is a smaller amount of carbides and the austenitic grain is able to grow more freely. Moreover, the optimum temperature determined experimentally for steel X30Cr 13 easily exceeds its total carbide dissolution temperature, so grain growth above this temperature occurs freely, uncontrolled by the carbides.

\subsection{Carbide dissolution}

To evaluate the specific influence of the heating temperature on the carbide dissolution which occurs during heating at a constant rate of $0.5 \mathrm{~K} \mathrm{~s}^{-1}$, image analysis was used to measure the area percentages of carbides in the microstructures of quenchings performed at a fast cooling rate. As in all the tests of this study, the steels were invariably kept at the different heating temperatures for $60 \mathrm{~s}$. Cooling rates of around $50 \mathrm{~K} \mathrm{~s}^{-1}$ were applied to avoid carbide precipitation during quenching and it was thus ensured that the percentages measured corresponded to the amounts of carbides in the states of austenization attained at the different heating temperatures.
Fig. 4 shows how the area percentage of carbides drops in these steels when the heating temperature is raised. The graphs demonstrate that the drop grows as the heating temperatures approach the total carbide dissolution temperatures for each steel [11]. In steel $\mathrm{X} 60 \mathrm{CrMoV} 14$ the optimum temperature is lower than the total carbide dissolution temperature, and $5.5 \%$ of carbides do not dissolve in the austenite at this optimum temperature. In steels X45CrMoV14 and $\mathrm{X} 45 \mathrm{Cr} 13$ there is a high level of carbide dissolution at their optimum temperatures because these are very similar to their respective total dissolution temperatures. Total carbide dissolution only occurs at the optimum temperature in steel $\mathrm{X} 30 \mathrm{Cr} 13$ because this temperature is higher than the total carbide dissolution temperature of this steel. In any case, regardless of the greater or lesser degree of dissolution reached at the optimum temperatures, the results in Fig. 4 indicate that a significant reduction of carbides occurs in the four steels between their corresponding conventional and optimum temperatures.

Without taking into account the influence of the carbide precipitation, which will be analysed later, it is clear that the carbides which do not dissolve during heating will be present in the final quenching microstructure of these steels. Consequently, the reduction of carbides at the optimum temperatures will, in principle, improve the corrosion resistance obtainable in these materials after heat-quenching treatment.

The heating temperature in this way has an important influence on the hardness and on the corrosion resistance of martensitic stainless steels. As will be seen below, the cooling rate is another very important factor because of its influence on both properties.

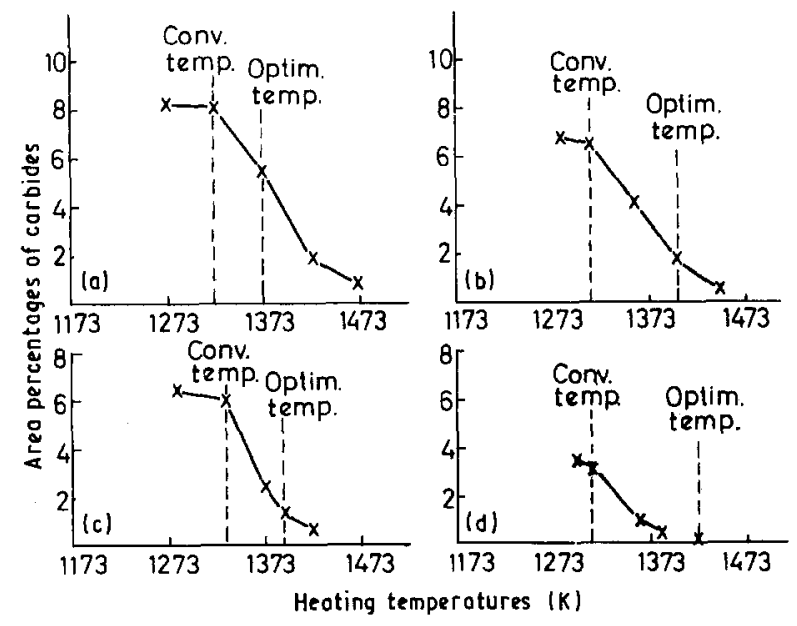

Figure 4 Variation of the area percentages of carbides in quenched structures at different heating temperatures. (a) X60CrMoV14, (b) X45CrMoV14, (c) X45Cr13, (d) X30Cr13. 


\section{Influence of the cooling rate}

\subsection{Hardness}

The experimental curves of variation of hardness in relation to the cooling rate, which are shown in Fig. 5, were obtained for each steel from the two states of austenization previously identified by their corresponding conventional and optimum temperatures. To analyse the variation of hardness in the quenching microstructures formed exclusively by martensite or by martensite and carbides, without perlite, the graphs in Fig. 5 show the results obtained at the cooling rates faster than the critical rates of total transformation into martensite $[11,12]$. To facilitate the plotting of the graphs, the hardness is shown in terms of the wellknown $\Delta t_{8 / 5}$ index, which is defined as the time which elapses during cooling at a constant rate from $1073 \mathrm{~K}$ to $773 \mathrm{~K}\left(800^{\circ} \mathrm{C}\right.$ to $\left.500^{\circ} \mathrm{C}\right)[13,14]$. The corresponding cooling rates are shown together with the logarithmic scale of $\Delta t_{8 / 5}$.

Fig. 5 shows that by raising the cooling rate, the hardness of the martensitic quenching microstructure of the four steels rises to a maximum value, after which it remains constant as the cooling rate rises. These results demonstrate that at the optimum quenching temperatures proposed in this study, not only the highest levels of hardness are obtained but also that to attain them slower cooling rates are required.

\subsection{Carbide precipitation}

Given the influence of the carbides on the corrosion resistance of martensitic stainless steels, an analysis was carried out of the influence of the cooling rate on the carbide precipitation which occurs during continuous cooling of these steels from their corresponding conventional and optimum temperatures

The measurements of the area percentage in carbides of the same quenching microstructures obtained in the tests described above show that no significant carbide precipitation occurs during cooling from the conventional temperatures. Regardless of the cooling rate, the area percentages of carbides measured on the quenching microstructures of the four steels from their corresponding conventional temperatures are almost identical to those given in Fig. 4 for the states of austenization attained at the conventional temperatures. These results are shown in Fig. 6 within a shaded zone. However, as Fig. 6 also shows, the area percentages in carbides measured on the quenching microstructures performed at the optimum temperatures of the four steels fall as the cooling rate rises until they reach minimum values which remain constant. In each steel these minimum values coincide with the carbide percentages indicated in Fig. 4 for the states of austenization attained at their optimum temperatures. According to these results, carbides will only be precipitated in these steels from their optimum temperatures at slower cooling rates than the rate at which this minimum value is reached. Faster cooling rates prevent carbide precipitation during cooling and the area percentage in carbides in the state of quenching will be the same as in the state of austenization.

Although in the four steels tested carbide precipitation occurs at its optimum temperatures, the results given in Fig. 6 show that throughout the range of cooling rates, the area percentages of carbides of the

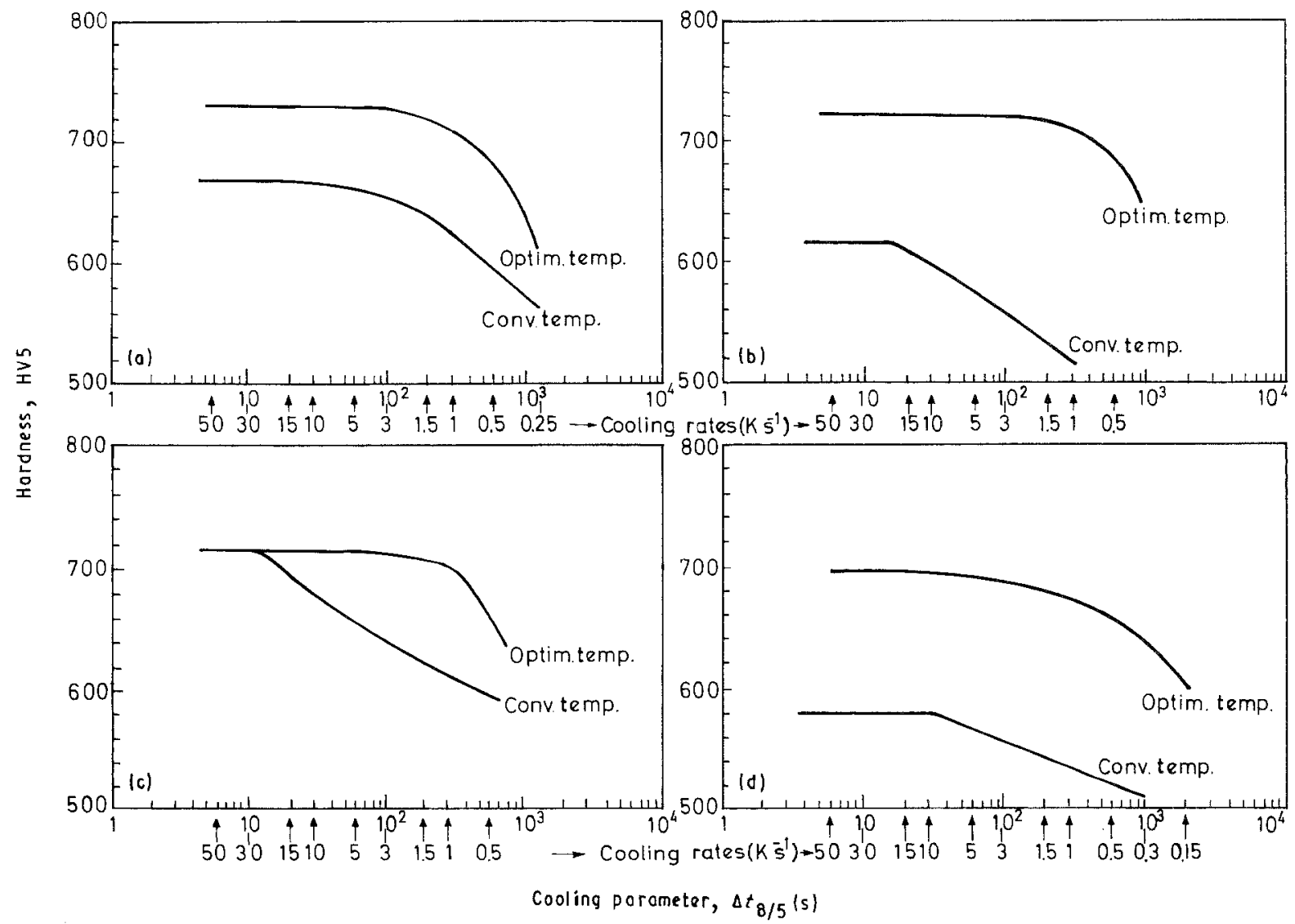

Figure 5 Influence of cooling rate on martensitic hardness. (a) $\mathrm{X} 60 \mathrm{CrMoV} 14$, (b) $\mathrm{X} 45 \mathrm{CrMoV} \mathbf{9}$, (c) $\mathrm{X} 45 \mathrm{Cr} 13$, (d) $\mathrm{X} 30 \mathrm{Cr} 13$. 


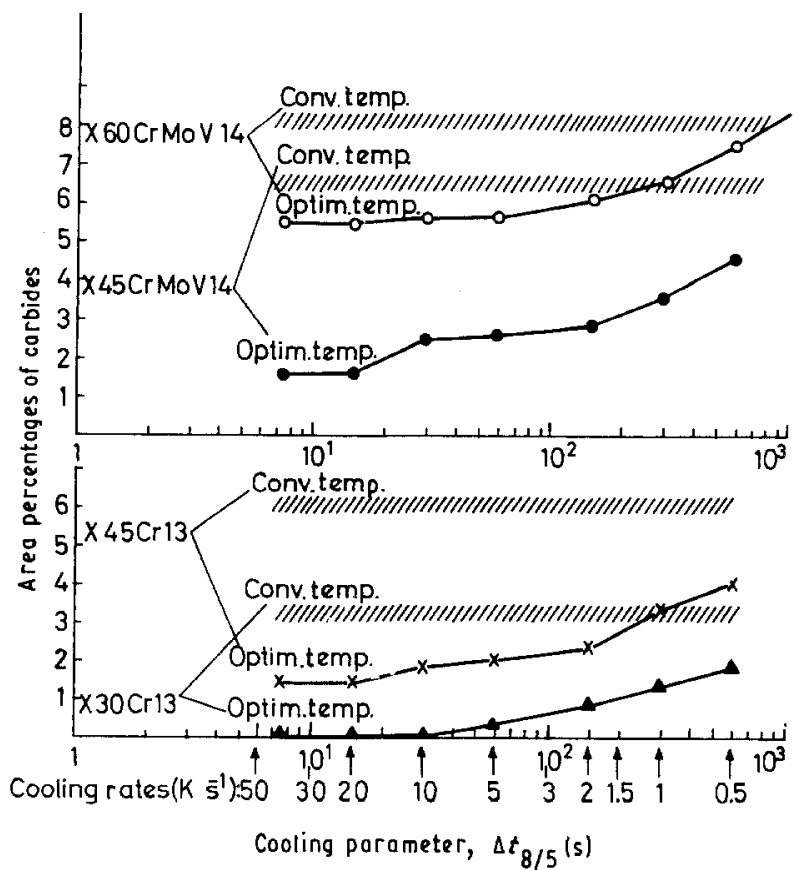

Figure 6 Influence of cooling rate on area percentages of carbides in quenched structures at conventional and optimum temperatures.

quenching microstructures performed at optimum temperatures are much lower than at conventional temperatures.

\section{Conclusions}

The analysis of the experimental results obtained in this study allow us to conclude that the typical quenching properties of these martensitic stainless steels can be optimized via the heating temperature. The optimum quenching temperatures proposed are higher than the conventional temperatures generally used in industrial practice and they provide high levels of hardness in these steels. In addition to verifying the optimization of the hardness, this study also confirmed that the rise of the heating temperature considerably lessens the amounts of carbides present in the quenching microstructures. A better corrosion behaviour may be expected when these steels are quenched at their optimum temperatures. Thus the dual objective of simultaneously optimizing their hardness and corrosion resistance properties will be attained.

It was also demonstrated that the austenitic grain size remains sufficiently fine at the optimum temperatures proposed, especially in the three steels with the highest carbon content. Consequently, we may conclude that the moderate grain growth which occurs between the conventional and optimum temperatures will not have any significant effect on the toughness properties of these steels in as-quenched condition.

From the experimental study of the effects caused by the cooling rate, it may be concluded that for the optimum quenching temperatures proposed here, not only are high levels of hardness reached but also slower cooling rates are needed to attain them. The possibility of obtaining high levels of hardness with slower cooling rates gives a considerable reduction in the risk of producing internal stresses, strains and cracks during heat-quenching treatment of these steels.

Finally, the absence of residual austenite in the microstructures obtained by quenching from the optimum temperatures [11], reinforces the idea that these temperatures are suitable for heat-quenching treatment of these martensitic stainless steels.

\section{References}

1. M. ATKINS, "Atlas of continuous cooling transformation diagrams for engineering steels" (British Steel Corporation, Sheffield, 1985) pp. 170-2.

2. Spanish Standard UNE 36-016-75, "Aceros inoxidables, forjados o laminados, de uso general" (Iranor, Madrid, 1981) pp. 199

3. AST M A 473-82. "Stainless and Heat-Resisting Steel Forging", ASTM Standards, Annual Book, Vol. 0105 (American Society for Testing and Materials, Philadelphia, PA 1984) p. 433.

4. K. H. PRABHUDEV, "Handbook of Heat Treatment of Steels" (Tata McGraw-Hill, New Delhi, 1988) pp. 702-4.

5. G. A. ROBERTS and R. A. CARY, "Tool Steels" (American Society for Metals, $\mathrm{OH}, 1980$ ) pp. 450-1.

6. G. DI CARPIO, "Los aceros inoxidables" (S. A. Ebrisa, Barcelona, 1987) pp. 181-5 (translation of "Gli Acciai Inossidabili", Ulrico Hoepli Editore, S.p.A, 1981).

7. H. ORDENBACH, "Les Aciers Inoxidables" (Technique et Documentation-Lavoisier, Paris, 1990) pp. 26-31, (translation of "Nichtrostende Stähle", Verlag Stahleisen mbH, Düsseldorf, 1989).

8. A. B. KINZEL and R. FRANKS, "The Alloys of Iron and Chromium", Vol. II, "High-Chromium Alloys" (McGraw-Hill, New York, 1940) pp. 117-26.

9. F. B. PICKERING, Int. Metals Rev. 211 (1976) 238.

10. C. GARCIA, L. F. ALVAREZ and M. CARSI, Proceedings of Mattech' 90, Int. J. Mater. Prod. Technol. 3 (1991) pp. 172-6.

11. L. F. ALVAREZ, Tesis Doctoral (Editorial de la Universidad Complutense de Madrid, Madrid, 1991) pp. 122-9, 182-96.

12. C. GARCIA, L. F. Alvarez and M. CARSI, Rev. Metal. Madrid. 4 (27) (1991) 236

13. W. STEVEN and C. MAYER, J. Iron Steel Inst. 1 (174) (1953) 33.

14. M. ECONOMOPOULOS, N. LAMBERT and L. HABRAKEN, "Diagrammes de Transformations des Aciers Fabriqués dans le Benelux" (CNRM, Bruxelles, 1967) pp. $39-40$

Received 28 October 1991

and accepted 11 August 1992 